\title{
Investigation on Efficiency of Repairing and Retrofitting Methods for Chloride induced Corrosion of Reinforced Concrete Structures
}

\author{
B.H.J. Pushpakumara, Sudhira De Silva and G.H.M.J. Subashi De Silva
}

\begin{abstract}
The corrosion of steel reinforcement bars is one of the major deterioration mechanisms of Reinforced Concrete (RC) structures. Once the corrosion signs appear on the concrete surface, it may be too late to prevent further corrosion. As a result, service life of RC structures would be reduced. Use of repairing and retrofitting methods at the appropriate time will contribute enormous saving of country budget, which is required for re-construction. This paper presents an experimental investigation of repairing and retrofitting methods for the RC structures corroded due to chloride attack. As repairing methods for delaminated areas of corroded RC structures, Fly Ash (FA) and Silica Fume (SF) mixed mortars were developed and their performances were evaluated. As retrofitting methods, Cathodic Protection (CP) and Electrochemical Chloride Extraction (ECE) were conducted. ECE method is similar to $\mathrm{CP}$ method except the anode was covered by $\mathrm{Ca}(\mathrm{OH})_{2}$ layer. $\mathrm{RC}$ beams with concrete of Grade 20 and reinforcement bars of $16 \mathrm{~mm}$ diameter were cast. Efficiency of both repairing and retrofitting methods was evaluated by measuring free and total chloride ion concentration and rust production. Efficiency of repairing and retrofitting methods was further evaluated by measuring resistivity and Rapid Chloride Permeability Test (RCPT) and current measurement, respectively. FA mixed mortar reduces the total chloride ion concentration near embedded steel reinforcement bars in concrete by $40 \%$ while SF mixed mortar reduces $25 \%$ compared to OPC mortar. FA and SF mixed mortars prevent the corrosion process by minimizing the diffusion of chloride ions into concrete. It was found that $\mathrm{CP}$ method removed around $49 \%$ of total $\mathrm{Cl}^{-}$while ECE method removed around $69 \%$ of total $\mathrm{Cl}^{-}$near the steel reinforcement of $\mathrm{RC}$ beams. Removing of total $\mathrm{Cl}^{-}$by ECE is grater (in $20 \%$ ) than that of by CP method. Chloride contaminated concrete that is still sound can be retrofitted by using $\mathrm{CP}$ and ECE methods and the spalled and detached concrete can effectively be repaired by using FA mixed mortars.
\end{abstract}

Keywords: Accelerated Corrosion Test Method (ACTM), chloride attack, corrosion, repairing mortars

\section{Introduction}

Sri Lanka is an Island surrounded by the Indian Ocean and has large number of Reinforced Concrete (RC) structures near the coastal belt. These structures are suffered by chloride ion induced corrosion; therefore the service life of these RC structures may be reduced. When use of the structures is critical, the authorities have to use reconstruction measures. As a result, considerable portion of country's budget are consumed for reconstruction of corroded RC structures.
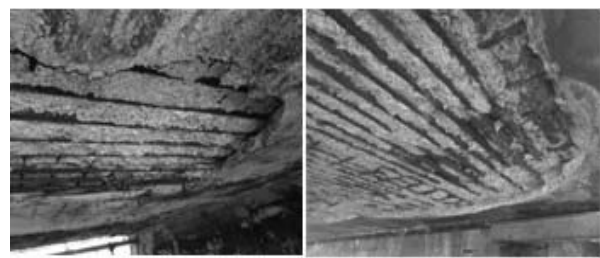

Figure 1 - Existing corroded bridge girders
The use of effective repairing and retrofitting methods at right time helps to increase the service life of RC structures, as result there will be enormous saving of country's budget. If a RC structure is cracked or spalled or delaminated (Figure 1), repairing of these damaged areas must be done using mortars before applying the retrofitting methods.

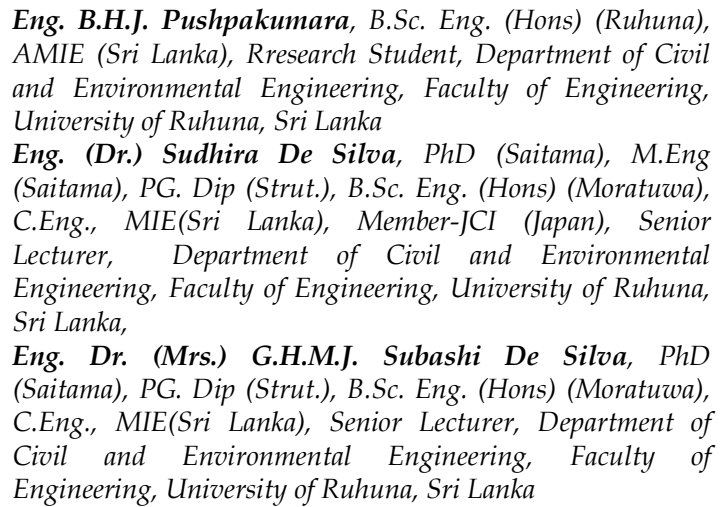

Eng. B.H.J. Pushpakumara, B.Sc. Eng. (Hons) (Ruhuna), AMIE (Sri Lanka), Rresearch Student, Department of Civil and Environmental Engineering, Faculty of Engineering, University of Ruhuna, Sri Lanka

Eng. (Dr.) Sudhira De Silva, PhD (Saitama), M.Eng (Saitama), PG. Dip (Strut.), B.Sc. Eng. (Hons) (Moratuwa), C.Eng., MIE(Sri Lanka), Member-JCI (Japan), Senior Lecturer, Department of Civil and Environmental Engineering, Faculty of Engineering, University of Ruhuna, Sri Lanka,

Eng. Dr. (Mrs.) G.H.M.J. Subashi De Silva, PhD (Saitama), PG. Dip (Strut.), B.Sc. Eng. (Hons) (Moratuwa), C.Eng., MIE(Sri Lanka), Senior Lecturer, Department of Civil and Environmental Engineering, Faculty of Engineering, University of Ruhuna, Sri Lanka 
Most of repairing mortars minimize the diffusion of chloride ions to steel reinforcements by increasing the density of repair mortar, producing chemical reaction with chloride ions, applying water proof materials and applying hydrophobic agents with repair mortars (Jennifer et al. [8]). These repair mortars could normally consist of more than one type of cement (special cement, like ultra-fine alumina cement), additions (silica fume, slag or fly ash), aggregates (normal, light weight and special type fillers), admixtures (such as plasticizers), air-entrainers and accelerators, polymer additives and fine polymer fibers (Saraswathy and Song [11]). The Fly Ash (FA) and Silica Fume (SF) are normally used during concrete batching to increase the density and strength. Therefore, FA and SF would be effective admixtures to increase the density of repairing mortars. According to Detwiler et al. [3], the optimal replacement percentage of cement (by mass) in concrete by using SF is between $6 \%$ and $8 \%$. The amount of FA between $25 \%$ and $60 \%$ of cement weight were normally used to produce sustainable, high performance concrete mixtures (Aggarwal et al. [1]).

Cathodic Protection (CP) is one of most effective retrofitting method for the corroded RC structures. CP works by using current, to shift the potential of reinforcement steel in negative direction. If the potential is shifted far enough so that all of the steel reinforcements behave as cathode, in which corrosion will be terminated. An advantage of using CP method as a retrofitting method for RC structures is that only spalled and detached concrete need to be repaired. Chloride contaminated concrete that is still sound (i.e., no any visible external damages like cracking and spalling) can remain in place, because the CP system prevents further corrosion and in fact, reduces the concentration of chloride ions adjacent to the protected reinforcement bars.

The Electrochemical Chloride ion Extraction (ECE) method, which is another retrofitting method, is similar to the CP method except that the anode in ECE method is covered by a chemical media. This chemical media absorbs $\mathrm{Cl}^{-}$which approach towards the anode area (i.e., concrete surface). ECE method is a new technology and it accelerates the efficiency of $\mathrm{CP}$ method by removing the $\mathrm{Cl}^{-}$effectively. The chemical media can be any of alkaline solutions which react with $\mathrm{Cl}^{-}$and produce chloride salt of particular cation (Virmani and Clemena [13]). Further, $\mathrm{Ca}(\mathrm{OH})_{2}$, which is an alkaline solution, would react with $\mathrm{Cl}^{-}$and produce $\mathrm{CaCl}_{2}$ salt. Formation of $\mathrm{CaCl}_{2}$ salt will prevent the present of free $\mathrm{Cl}^{-}$near anode, which helps to continue current path without restriction. Therefore, $\mathrm{Ca}(\mathrm{OH})_{2}$ would be an effective chemical media for ECE method.

Use of repairing and retrofitting methods at right time, helps to increase service life of RC structures which save the financial expenditures of a country for reconstruction. Therefore, it is an urgent need to introduce suitable repairing and retrofitting methods for RC structures in Sri Lanka.

The objectives of this study are;

- To identify the performances of Fly Ash and Silica Fume mixed mortars for corrosion

- To determine and compare the performances of Cathodic Protection and Electrochemical Chloride ion Extraction methods

- To identify the performances of $\mathrm{Ca}(\mathrm{OH})_{2}$ as a new chemical media for Electrochemical Chloride ion Extraction method

\section{Methodology}

Fly Ash (FA) and Silica Fume (SF) mixed mortars were evaluated as mortars for repairing spalled and detached RC structures. Cathodic Protection (CP) and Electrochemical Chloride ion Extraction (ECE) were evaluated as retrofitting methods for chloride ion contaminated concrete which is still sound.

\subsection{Repairing Methods}

Five RC beams were cast with concrete of Grade 20 and reinforcement bar diameter of 16 $\mathrm{mm}$. Three steel stirrups with diameter of $6 \mathrm{~mm}$ were used in each steel reinforcement bar cage. Size of the RC beams is $380 \mathrm{~mm} \times 80 \mathrm{~mm} \times 130$ $\mathrm{mm}$ and the clear cover is $10 \mathrm{~mm}$ (Figure 2).

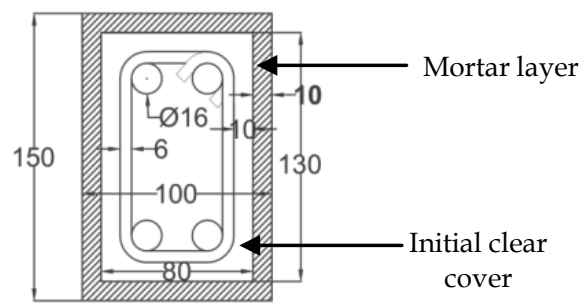

Figure 2 - Schematic diagram of cross section of $\mathrm{RC}$ test beam (Dimensions are in $\mathrm{mm}$ )

All the RC beams were immersed in water for 28 days of curing. After curing, RC beams were covered by using mortar layers. The mortars were prepared with the cement sand ratio of 
1:3. Surfaces of RC beams were chipped and 10 mm thick mortar layers were applied as the final clear cover was to be $20 \mathrm{~mm}$ (Figure 2). Cement in the mortar was partially replaced by adding FA and SF on weight basis. Two beams were treated with $50 \%$ of FA mixed mortar and other two beams were treated with $10 \%$ of SF mixed mortar. The remaining $\mathrm{RC}$ beam was used as the control beam with $10 \mathrm{~mm}$ thick OPC mortar layer.

After applying mortars, RC beams were again immersed in water for 28 days of curing. After 28 days curing, the $\mathrm{RC}$ beams were subjected to Accelerated Corrosion Test Method (ACTM) until $0.2 \mathrm{~mm}$ corrosion crack width was attained. Then, free and total chloride ion concentration, rust production and resistivity of the RC beams were determined. In addition, chloride ion permeability through mortars was evaluated by conducting Rapid Chloride Permeability Test (RCPT).

\subsection{Retrofitting Methods}

Eight RC beams having the sizes of $400 \mathrm{~mm} \mathrm{x}$ $100 \mathrm{~mm} \times 150 \mathrm{~mm}$ were cast using Grade 20 concrete. Four steel reinforcement bars with diameter of $16 \mathrm{~mm}$ were tied into a cage by using three steel stirrups, whose diameter is 6 $\mathrm{mm}$. Two wires were set to each beam for the purpose of applying current to the beams during experiments. The cover depth was kept as $20 \mathrm{~mm}$. All RC beams were immersed in a water tank for 28 days of curing.

Corrosion in seven RC beams was accelerated by performing ACTM until $0.2 \mathrm{~mm}$ corrosion crack width was attained. The remained RC beam was not subjected to ACTM and it was labelled as "before performing ACTM beam" and used as control beam to identify effect of ACTM on corrosion. This control beam and one beam out of seven corroded beams by using ACTM were tested for free and total chloride ion concentration and rust production measurements in order to identify the effect of ACTM on corrosion of RC beams.

Four RC beams (i.e., two beams for each retrofitting method) were retrofitted by using $\mathrm{CP}$ and ECE methods. Other two beams were used as control beams. Three of these beams (i.e., control beam and one beam from each retrofitting method) were tested for free and total chloride ion concentration and rust production measurements in order to determine effectiveness of each retrofitting method. The remaining three beams; (i.e., control beam and one beam from each retrofitting method) were again subjected to ACTM. Resistivity of these three RC beams was measured by using Resistivity meter (James RM8000).

\subsubsection{Cathodic Protection (CP) Method}

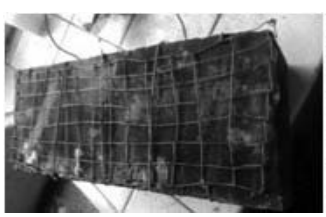

(a)

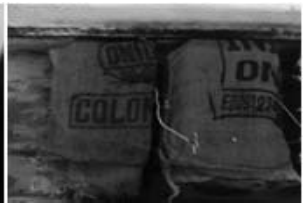

(b)
Figure 3 - CP method procedure (a) Copper mesh was fixed (b) Wet sags were laid on the beams

Copper meshes were connected to $400 \mathrm{~mm} \mathrm{x}$ $150 \mathrm{~mm}$ surface of each RC beam as shown in Figure 3(a) and the mesh was covered by using wet sags for the purpose of contacting the mesh with concrete surface (Figure 3(b)). The current was supplied by using a Direct Current (DC) power supply unit; the positive terminal was connected to copper mesh (i.e., anode) and the negative terminal was connected to embedded steel reinforcements which would be the cathode. Since the higher current flow cause hydrogen ion generation, current should be maintained below 1 A (Jennifer et al. [8]). Hydrogen ion generation can cause the brittle failure of RC structures. Therefore, a current of 0.3 A was supplied initially. The current of 0.3 A could be supplied with the voltage of $11.5 \mathrm{~V}$. This lead to which the current was supplied to the system with a constant voltage of $11.5 \mathrm{~V}$ and was monitored with time until a negligible current reading (current reading $<0.1 \mathrm{~A}$ ) was observed.

\subsubsection{Electrochemical Chloride ion Extraction (ECE) Method}

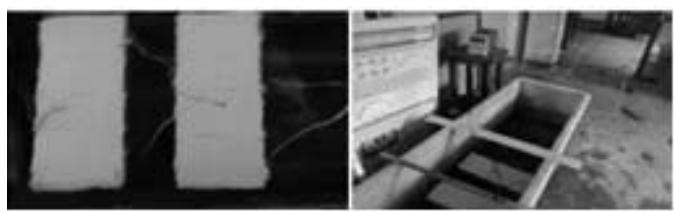

(a)

(b)

Figure 4 - ECE method (a) $\mathrm{Ca}(\mathrm{OH})_{2}$ layer was laid on copper mesh (b) Experimental

In this method, copper meshes were connected to $\mathrm{RC}$ beams as similar to that in CP method presented in Section 2.2.1. The meshes were covered by using hydrated lime $\left(\mathrm{Ca}(\mathrm{OH})_{2}\right)$ layer of $5 \mathrm{~mm}$ thickness (Figure 4(a)). Similar to the CP method, electric system was prepared and the current was supplied (Figure 4(b)). In 
ECE method also, the current was monitored with time until a negligible reading (i.e., current reading $<0.1 \mathrm{~A}$ ) was observed.

\subsection{Laboratory Experiments}

\subsubsection{Accelerated Corrosion Test Method}

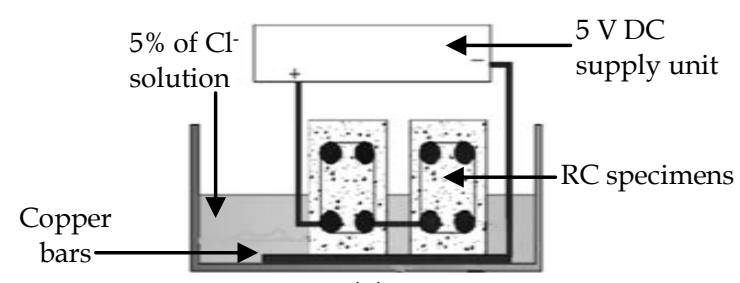

(a)

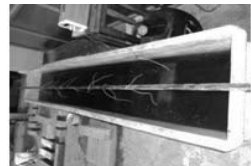

(b)

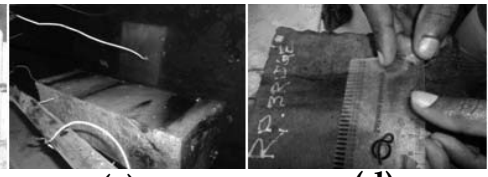

(c) (d)
Figure 5 - (a) ACTM procedure (b) DC was supplied (c) Corroded beam (d) Measuring the crack width

ACTM was based on the electrochemical polarization principle. The corrosion of embedded steel reinforcement bars were accelerated as specified in FDOT 2000 [4] and Sahmaran et al. [10]. The beams were immersed in a sea water container where the $\mathrm{Cl}^{-}$ concentration of sea water was improved up to $5 \%$ by adding $\mathrm{NaCl}$. The $\mathrm{NaCl}$ concentration of sea water sample was measured by using titration against $\mathrm{AgNO}_{3}$ and was observed as $34.8 \mathrm{~g} / 1$. The current for the system was supplied by using a DC power supply unit (Figure 5(a) and 5(b)). The positive terminal of the unit was connected to the embedded steel reinforcement bars and the negative terminal was connected to the copper bars which were placed under the RC beams. Then, a small current was supplied to the system with the constant voltage $(5 \mathrm{~V})$. Finally, the corrosion crack width was monitored with the time as shown in Figure 5(d), until $0.2 \mathrm{~mm}$ corrosion crack width was attained.

\subsubsection{Free and Total Chloride ion Concentration}

Test samples were prepared by collecting the concrete powder at nine locations of each RC beam; three points of $400 \mathrm{~mm} \times 150 \mathrm{~mm}$ surface: centre point and two points $(100 \mathrm{~mm}$ away from the centre, at both sides). At each point, samples were collected at $20 \mathrm{~mm}, 40 \mathrm{~mm}$ and $60 \mathrm{~mm}$ depth. For each beam, the concrete powder samples, which were collected at the same depth, were mixed and separately sieved through $75 \mu \mathrm{m}$ sieve pan. For each depth, two samples of $5 \mathrm{~g}$ were prepared to measure total and free chloride ion concentrations.

One sample $(5 \mathrm{~g})$ was mixed with $50 \mathrm{ml}$ of 0.05 mol/1 nitric acid $\left(\mathrm{HNO}_{3}\right)$ and stirred for 10 minutes using a magnetic stirrer to extract acidsoluble chlorides which were mostly equivalent to total chloride ions. Free chloride ion concentration was measured using the remaining $5 \mathrm{~g}$ sample. The sample was mixed with $50 \mathrm{ml}$ distilled water and stirred for 10 minutes using a magnetic stirrer to extract water-soluble chlorides ions which were mostly equivalent to free chloride ions. Each solvent sample was filtered through a filter paper. Finally, all filtered samples were titrated against silver nitrate $\left(\mathrm{AgNO}_{3}\right)$ and the free and total chloride ion concentrations were measured.

\subsubsection{Rust Production}

Rust production of embedded steel reinforcement was measured by using two methods: rust weight and reduction in bar diameter. The steel bars were carefully removed from the beams and the bar surface was scrapped in order to collect rust. The weight of the collected rust was measured. The bar diameter was measured by using a vernier calliper and the reduction in bar diameter was determined. The average values of rust weights and reduction in bar diameter were calculated to determine the rust production of steel bars.

\subsubsection{Resistivity}

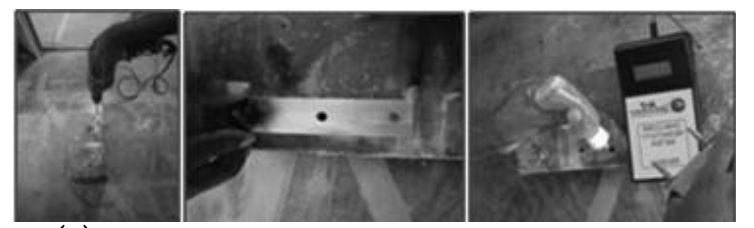

(a)

(b)

(c)

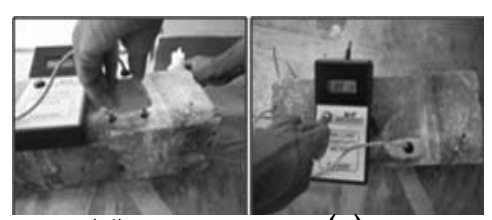

(d)

(e)

Figure 6 - Procedure of measuring resistivity

(a) Preparation of $8 \mathrm{~mm}$ depth hole

(b) Preparation of additional hole at $50 \mathrm{~mm}$ apart (c) Use of conductive gel (d) Placing Resistivity meter (e) Measuring resistivity

Resistivity meter (James RM-8000), which is capable in assessing the possible rate of corrosion in reinforcement bars with the electric 
resistivity measurement method, was used to measure the internal corrosion level. Two holes with the diameter of $6 \mathrm{~mm}$ and the depth of 8 $\mathrm{mm}, 50 \mathrm{~mm}$ apart (along the reinforcement bar), were drilled on the surface of beam (Figure 6(a)). The stainless steel template plate, which was given with the equipment, was used to identify the location of the additional holes (Figure 6(b)). The two holes were filled with dispenser conductive gel (Figure 6(c)). This was necessary to create proper contact between concrete and Resistivity meter probes, which, was connected to the holes as shown in Figure 6(d). Resistivity (in k Ohms cm) was measured and the possible corrosion rate (possible corrosion rate for resistivity: $<5$ = very high, 5$10=$ High, $10-20=$ Moderate to low and $>20=$ Insufficient) of steel reinforcement bars was determined by referencing the resistivity levels provided with the Resistivity meter (Instruction manual [9]).

\subsubsection{Rapid Chloride Permeability Test}

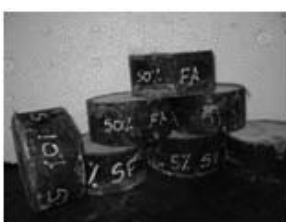

(a)

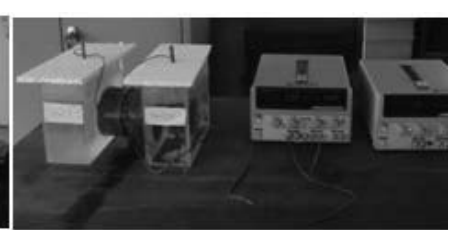

(b)
Figure 7 - RCPT setup (a) Repair mortar cylinders (b) RCPT experimental setup

Rapid Chloride Permeability Test (RCPT) was performed for FA mixed and SF mixed mortars to evaluate permeability as specified in ASTM C1202 (Ganesan et al. [5]). Twenty one mortar cylinders (i.e., three cylinders for each mortar percentage and three OPC mortar cylinders) (Figure 7 (a)) having a diameter of $100 \mathrm{~mm}$ and a thickness of $50 \mathrm{~mm}$ were cast by using 1:3 cement sand mortar; cement in the mortar was partially replaced by FA and SF, in weight basis, as summarized in Table 1.

Table1 - Admixture replacement level

\begin{tabular}{|c|c|}
\hline Type of mortar & $\begin{array}{c}\text { Admixture replacement } \\
\text { percentages }(\%)\end{array}$ \\
\hline Control (OPC) & 0 \\
\hline Fly Ash (FA) & $25,50,75$ \\
\hline Silica Fume (SF) & $5,10,15$ \\
\hline
\end{tabular}

After 90 days of curing, all the cylinders were set to the RCPT experimental setup (Figure 7(b)). Two copper electrodes were connected to terminals and the positive terminal was immersed in $\mathrm{NaOH}$ solution (with possessed normality of $0.3 \mathrm{~N}$ ) reservoir while the negative terminal was immersed in $3 \%$ of $\mathrm{NaCl}$ solution reservoir. The cylinders were connected between two reservoirs as shown in Figure 7(b). A constant voltage of $60 \mathrm{~V}, \mathrm{DC}$ was supplied to the system and current across the cylinders were recorded at 30 minute intervals over the period of 6 hours. The total Charge Passed (CP) through the specimen was computed by Simpson's rule (Equation 1) as specified in the ASTM C1202 (Ganesan et al. [5]).

$$
\begin{gathered}
C P=900\left[I_{0}+2 I_{30}+2 I_{60}+2 I_{t}+\cdots+2 I_{330}\right. \\
\left.+2 I_{360}\right]---(1)
\end{gathered}
$$

where $C P$ is total charge passed in coulombs, $I_{0}$ is the initial current in Ampere $(A)$ and $I_{t}$ is current in Ampere (A) at time $t$, measured in minutes.

\section{Results}

\subsection{Efficiency of Repairing Mortars}

Efficiency of the repairing mortars was investigated by free and total chloride ion concentration, rust production, resistivity and permeability and is presented in this section.

\subsubsection{Free and Total Chloride ion Concentration}

Figures 8 and 9 show free and total $\mathrm{Cl}^{-}$ concentration of RC beams, respectively. The $\mathrm{Cl}^{-}$concentration was determined at four different stages: before performing ACTM, after performing ACTM for OPC, FA mixed and SF mixed mortar laid RC beams.

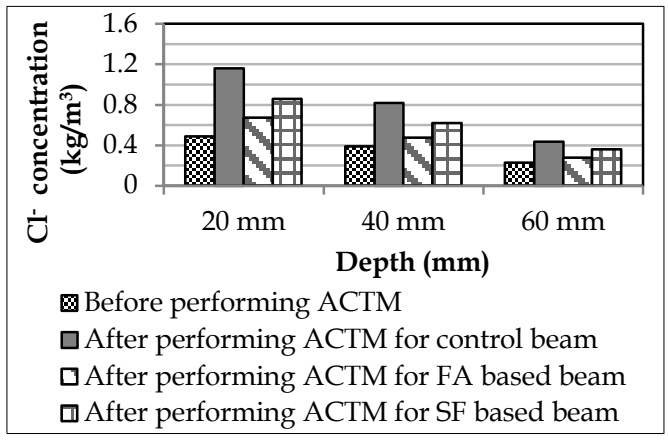

Figure 8 - Free chloride ion concentration

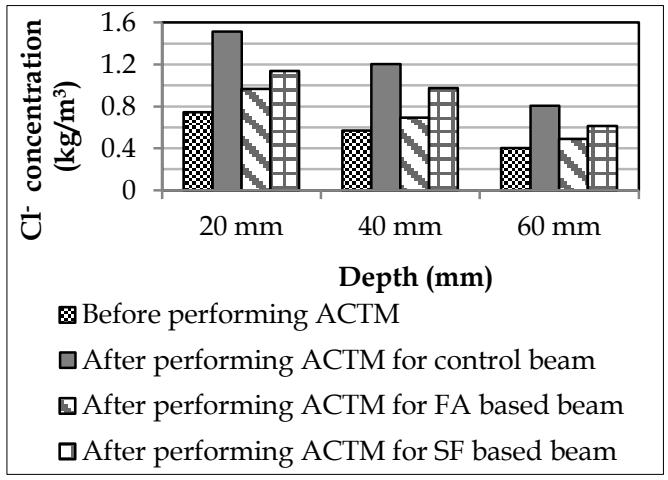

Figure 9- Total chloride ion concentration 
It was observed that free and total $\mathrm{Cl}^{-}$ concentrations decreased with increasing depth of the beam. This trend was common at all the four stages. For all depth levels (i.e., $20 \mathrm{~mm}, 40$ $\mathrm{mm}$ and $60 \mathrm{~mm}$ ), total $\mathrm{Cl}^{-}$concentration was higher than the free $\mathrm{Cl}^{-}$concentration. Generally, $\mathrm{Cl}^{-}$concentration is greater after performing ACTM compared to the concentration before performing ACTM. After performing ACTM, in repaired beams both free and total $\mathrm{Cl}^{-}$concentrations were less than those for the control beam. At $20 \mathrm{~mm}$ depth level, after performing ACTM, the total $\mathrm{Cl}^{-}$ concentration is $1.514 \mathrm{~kg} / \mathrm{m}^{3}$ for OPC mortar. At the same depth, FA and SF mixed mortar applied beams which were subjected to ACTM simultaneously with the OPC mortar applied beam, have lower $\mathrm{Cl}^{-}$concentrations: 0.97 $\mathrm{kg} / \mathrm{m}^{3}$ for FA mixed mortar and $1.14 \mathrm{~kg} / \mathrm{m}^{3}$ for SF mixed mortar, respectively.

\subsubsection{Rust Production}

Rust weights and reduction in bar diameter of repaired RC beams, which were tested after performing ACTM, are shown in Table 2.

Table 2- Rust production

\begin{tabular}{|c|c|c|c|c|}
\hline Insp & ction Stage & 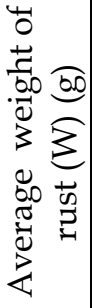 & 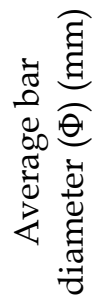 & 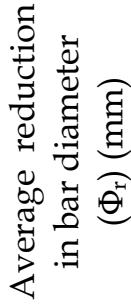 \\
\hline Init & condition & 0 & 16 & 0 \\
\hline & OPC mortar & 7.8 & 13.57 & 2.43 \\
\hline 屯ี & $\begin{array}{l}\text { FA mixed } \\
\text { mortar }\end{array}$ & 1.76 & 15.81 & 0.19 \\
\hline 《 & $\begin{array}{l}\text { SF mixed } \\
\text { mortar }\end{array}$ & 3.64 & 14.75 & 1.25 \\
\hline
\end{tabular}

It can be seen from Table 2 that, in the FA and SF mixed mortar applied beams, the average weight of rust and reduction in bar diameter (after performing ACTM) were lesser values compared to that of OPC mortar applied beams. The rust production (rust weight $(\mathrm{W})$ and bar diameter reduction $\left(\Phi_{\mathrm{r}}\right)$ ) of beams repaired with FA mixed mortar $(\mathrm{W}=1.76 \mathrm{~g}$ and $\Phi_{\mathrm{r}}=0.19 \mathrm{~mm}$ ) was lower than that of the beam repaired with $S F$ mixed mortar $(\mathrm{W}=3.64 \mathrm{~g}$ and $\left.\Phi_{\mathrm{r}}=1.25 \mathrm{~mm}\right)$.

\subsubsection{Resistivity}

Resistivity of RC beams (OPC, and $50 \%$ of FA and $10 \%$ of SF mixed mortar applied) which were subjected to ACTM is shown in Table 3.

Table 3- Resistivity of mortars

\begin{tabular}{|c|c|}
\hline $\begin{array}{c}\text { Mortar } \\
\text { condition }\end{array}$ & $\begin{array}{c}\text { Average resistivity } \\
(\mathrm{k} \mathrm{Ohms} \mathrm{cm})\end{array}$ \\
\hline OPC & 1.8 \\
\hline $50 \%$ of $\mathrm{FA}$ & 12.0 \\
\hline $10 \%$ of $\mathrm{SF}$ & 9.05 \\
\hline
\end{tabular}

It has been clearly seen that resistivity in the OPC mortar applied beam was very much lower (i.e., $1.8 \mathrm{k}$ ohms $\mathrm{cm}$ ) compared to that of FA and SF mixed mortar applied beams (FA = $12.0 \mathrm{k} \mathrm{Ohms} \mathrm{cm}$ and SF $=9.05 \mathrm{k} \mathrm{Ohms} \mathrm{cm}$ ). The resistivity of beams repaired by FA mixed mortar is slightly larger than beams repaired by SF mixed mortar.

\subsubsection{Rapid Chloride Permeability Test}

Variation of current with time for the FA mixed and SF mixed mortar cylinders is shown in Figures 10 and 11, respectively.

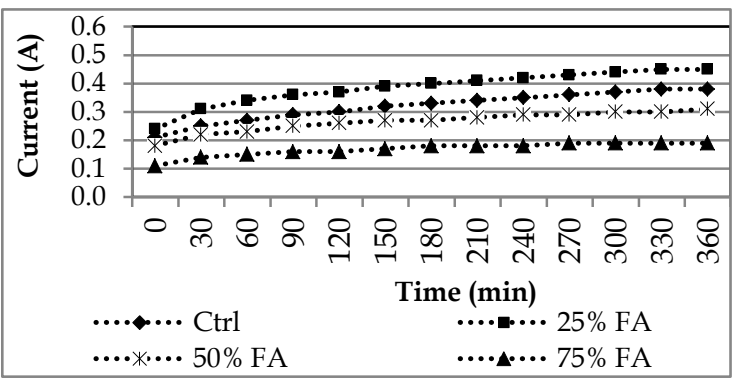

Figure 10- Current measurement of RCPT for FA mixed mortar

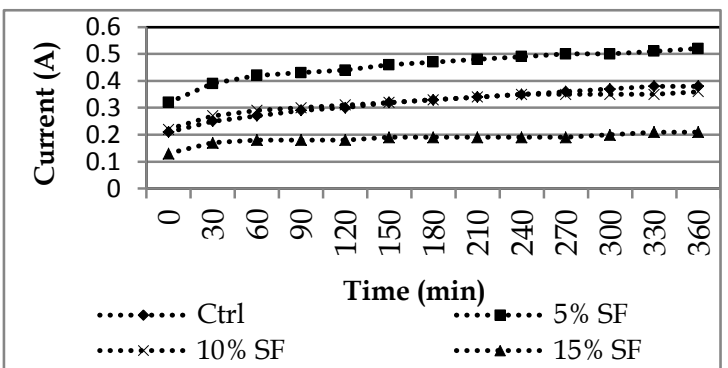

Figure 11- Current measurement of RCPT for SF mixed mortar

The current pass through the specimen decreases with increasing both FA and SF content in the mortars. This trend is clear from $25 \%$ to $75 \%$ of FA and from $5 \%$ to $15 \%$ of SF, although the trend is not clear when increasing FA content from $0 \%$ to $25 \%$ and SF content from $0 \%$ to $5 \%$ in the specimen. The calculated average charge passed (using Equation 1, 
Figures 10 and 11) across the mortar cylinders is shown in Figure 12.

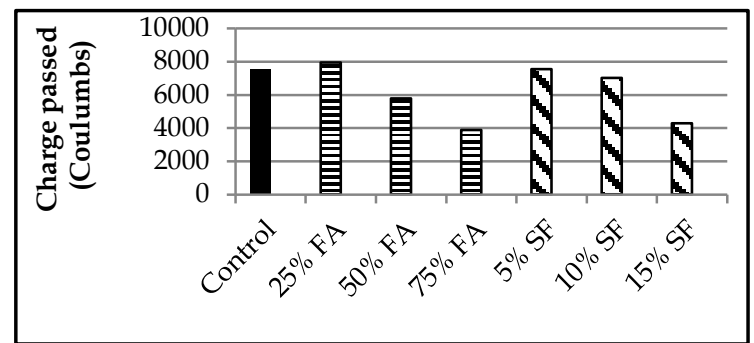

Figure 12- Charge passed average value

The charge passed values decrease with increasing of both FA and SF percentages. The average charge passed across the mortar cylinders cast by using mortar of having $75 \%$ of FA and $15 \%$ of SF are $3873 \mathrm{C}$ and $4278 \mathrm{C}$, respectively. These values are lower compared to OPC mortar cylinder (7518 C).

\subsection{Efficiency of Retrofitting Methods}

This section presents the efficiency of retrofitting methods (CP and ECE) that were evaluated by using chloride ion concentration, rust production and resistivity of RC beams and current passed through RC beams.

\subsubsection{Free and Total Chloride ion Concentration}

Figures 13 and 14 show the free and total $\mathrm{Cl}^{-}$ concentration, respectively, for the depth level of $20 \mathrm{~mm}, 40 \mathrm{~mm}$ and $60 \mathrm{~mm}$ at the four stages.

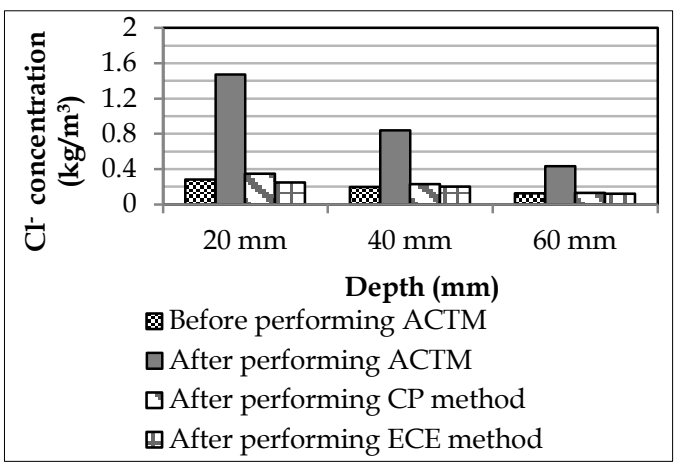

Figure 13- Free chloride ion concentration

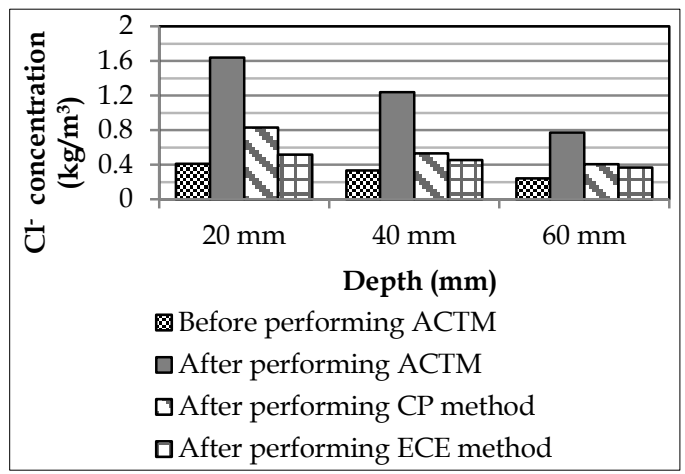

Figure 14- Total chloride ion concentration
The free and total $\mathrm{Cl}^{-}$concentrations were greater after performing ACTM. Both free and total $\mathrm{Cl}^{-}$concentrations decreased with increasing depth. Comparing Figures 13 and 14, it can be clearly seen that for all depths, the total $\mathrm{Cl}^{-}$concentration was higher than the free $\mathrm{Cl}^{-}$concentration. For all depths, both $\mathrm{Cl}^{-}$ concentrations were reduced after applying retrofitting methods. At $20 \mathrm{~mm}$ depth, the total $\mathrm{Cl}^{-}$concentration of control beam (nonretrofitted), after performing ACTM, is 1.64 $\mathrm{kg} / \mathrm{m}^{3}$ while it is $0.831 \mathrm{~kg} / \mathrm{m}^{3}$ for the beam retrofitted by the $\mathrm{CP}$ method and is 0.516 $\mathrm{kg} / \mathrm{m}^{3}$ for the beam retrofitted by the ECE method. At the same depth level, the free $\mathrm{Cl}^{-}$ concentration of control beam (non-retrofitted), after performing ACTM, is $1.471 \mathrm{~kg} / \mathrm{m}^{3}$ while it is $0.346 \mathrm{~kg} / \mathrm{m}^{3}$ for the beam retrofitted by the $\mathrm{CP}$ method and is $0.25 \mathrm{~kg} / \mathrm{m}^{3}$ for the beam retrofitted by the ECE method. The free and total $\mathrm{Cl}^{-}$concentrations of beams with the condition of before performing ACTM are 0.282 $\mathrm{kg} / \mathrm{m}^{3}$ and $0.41 \mathrm{~kg} / \mathrm{m}^{3}$, respectively, at $20 \mathrm{~mm}$ depth level.

\subsubsection{Rust Production}

Table 4 shows the average weight of the rust production and reduction in bar diameter of embedded steel reinforcements.

\section{Table 4- Rust production}

\begin{tabular}{|c|c|c|c|}
\hline Inspection Stage & 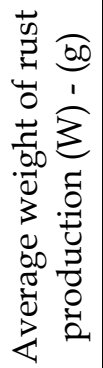 & 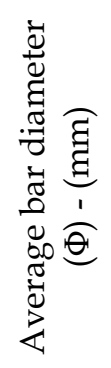 & 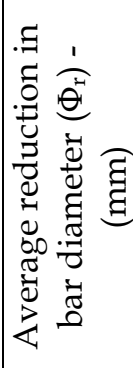 \\
\hline Initial condition & 0 & 16 & 0 \\
\hline $\begin{array}{c}\text { After performing } \\
\text { ACTM }\end{array}$ & 3.5 & 15.56 & 0.44 \\
\hline $\begin{array}{l}\text { After retrofitting by } \\
\text { CP method }\end{array}$ & 4 & 15.48 & 0.52 \\
\hline $\begin{array}{l}\text { After retrofitting by } \\
\text { ECE method }\end{array}$ & 3.75 & 15.53 & 0.47 \\
\hline $\begin{array}{l}\text { Control specimen } \\
\text { (without retrofitting) }\end{array}$ & 4.28 & 15.41 & 0.59 \\
\hline
\end{tabular}

The weight of the rust and the reduction in bar diameter were lower for the beams retrofitted with CP and ECE methods, compared with that of control beams. There was a negligible amount of rust production in retrofitted beams. The rust (rust weight $(\mathrm{W})$ and reduction in bar diameter $\left(\Phi_{\mathrm{r}}\right)$ ) produced in beams treated by $\mathrm{CP}$ 
method $\left(\mathrm{W}=4 \mathrm{~g}\right.$ and $\left.\Phi_{\mathrm{r}}=0.52 \mathrm{~mm}\right)$ were greater than that in the beams retrofitted by ECE method $\left(\mathrm{W}=3.75 \mathrm{~g}\right.$ and $\left.\Phi_{\mathrm{r}}=0.47 \mathrm{~mm}\right)$. As mentioned in the methodology, retrofitting methods were applied on the corroded beams (after performing ACTM). Therefore, rust is already produced on the bar surface. Comparing to after performing ACTM stage, the rust production and reduction in bar diameter of CP method $\left(\Delta \mathrm{W}=0.5 \mathrm{~g}\right.$ and $\Delta \Phi_{\mathrm{r}}=$ $0.8 \mathrm{~mm})$ and ECE method $\left(\Delta \mathrm{W}=0.25 \mathrm{~g}\right.$ and $\Delta \Phi_{\mathrm{r}}$ $=0.03 \mathrm{~mm}$ ) are lesser than that of control beam $\left(\Delta \mathrm{W}=0.78 \mathrm{~g}\right.$ and $\left.\Delta \Phi_{\mathrm{r}}=0.15 \mathrm{~mm}\right)$.

\subsubsection{Resistivity}

Table 5 shows comparison of resistivity of beams, retrofitted by using $\mathrm{CP}$ and ECE methods.

Table 5- Comparison of resistivity

\begin{tabular}{|c|c|}
\hline Beam description & $\begin{array}{c}\text { Resistivity } \\
\text { (k Ohms cm })\end{array}$ \\
\hline Control beam & 0.7 \\
\hline Beam retrofitted by CP & 3.1 \\
\hline Beam retrofitted by ECE & 4.5 \\
\hline
\end{tabular}

From Table 5, it can be seen that the resistivity of the control beam was $0.7 \mathrm{k} \mathrm{Ohms} \mathrm{cm}$, which is significantly lower compared with the resistivity of other beams: beam retrofitted by $\mathrm{CP}$ method gives $3.1 \mathrm{k}$ Ohms $\mathrm{cm}$ while beam retrofitted by ECE gives $4.5 \mathrm{k}$ Ohms. The resistivity ofthe RC beam retrofitted by ECE method was slightly higher than that of the RC beam retrofitted by $\mathrm{CP}$ method.

\subsubsection{Current}

For $\mathrm{CP}$ method, the initial current reading was $0.3 \mathrm{~A}$ for the first mesh, $0.23 \mathrm{~A}$ for the second mesh, and $0.16 \mathrm{~A}$ for the third mesh (the system was not continued with replacing third copper mesh after observing negligible current). Therefore the total current reduction was 0.14 A. The total time for the beam retrofitted by $\mathrm{CP}$ method was 31 days.

For ECE method, the initial current reading was observed as $0.5 \mathrm{~A}$. The initial current reading for the second mesh was $0.29 \mathrm{~A}$, and for the third mesh it was $0.17 \mathrm{~A}$ (the system was not continued with third mesh). The total current reading reduction was determined as $0.33 \mathrm{~A}$. The total time for beam retrofitted by ECE method was 23 days.

\section{Discussion}

According to the JSCE (2001), the critical $\mathrm{Cl}^{-}$ concentration is $0.3 \sim 0.6 \mathrm{~kg} / \mathrm{m}^{3}$ (Veerachai et al. [12]). Further, according to the JSCE (2001), when the $\mathrm{Cl}^{-}$concentration exceeds $1.2 \sim 2.4$ $\mathrm{kg} / \mathrm{m}^{3}$, the corrosion incorporating microcracks might be initiated (Veerachai et al. [12]). Simply, when the $\mathrm{Cl}^{-}$concentration of $\mathrm{RC}$ beams is higher than $0.6 \mathrm{~kg} / \mathrm{m}^{3}$, the critical $\mathrm{Cl}^{-}$ level was initiated (i.e., corrosion risk initiate) and when it was $1.2 \mathrm{~kg} / \mathrm{m}^{3}$, the corrosion is initiated on embedded steel reinforcement. The threshold $\mathrm{Cl}^{-}$concentration for onset corrosion is considered as $1.2 \mathrm{~kg} / \mathrm{m}^{3}$ (Gunesekara et al. [6]).

\subsection{Repairing Mortar}

Relatively high percentage of SF makes the concrete expensive and causes the difficulties in mixing and finishing. In the current study, 10\% of SF and $50 \%$ of FA were used in producing mortars with high density and high strength, while reducing the difficulties in mixing and finishing. Further, 5\%, 10\% and $15 \%$ of SF and $25 \%, 50 \%$ and $75 \%$ of FA mixed mortars were used to identify optimum level of admixture percentages for reducing the $\mathrm{Cl}^{-}$diffusion, which was investigated by using RCPT.

The most critical depth region related to corrosion was considered as less than $20 \mathrm{~mm}$ depth, because steel reinforcements were embedded to the depth of $20 \mathrm{~mm}$. The total $\mathrm{Cl}^{-}$ concentration, at $20 \mathrm{~mm}$ depth level of OPC mortar applied beam $\left(1.514 \mathrm{~kg} / \mathrm{m}^{3}\right)$ (Figure 9) is higher than threshold value of $1.2 \mathrm{~kg} / \mathrm{m}^{3}$, hence the beam was corroded. The total $\mathrm{Cl}^{-}$ concentrations of FA and SF mixed mortar applied beams $\left(\mathrm{FA}=0.97 \mathrm{~kg} / \mathrm{m}^{3}\right.$ and $\mathrm{SF}=1.14$ $\mathrm{kg} / \mathrm{m}^{3}$ ) were less than the threshold value of $1.2 \mathrm{~kg} / \mathrm{m}^{3}$, hence the corrosion risk is minimized. The total $\mathrm{Cl}^{-}$reduction, at $20 \mathrm{~mm}$ depth level, in the beam repaired with FA mixed mortar was $0.544 \mathrm{~kg} / \mathrm{m}^{3}$ and in the beam repaired with SF mixed mortar was 0.374 $\mathrm{kg} / \mathrm{m}^{3}$ (Figure 9). FA mixed mortar reduces $\mathrm{Cl}^{-}$ concentration near embedded steel reinforcement by $36 \%$, while SF mixed mortar reduces $25 \%$ of $\mathrm{Cl}^{-}$concentration. Therefore, FA mixed mortar prevents the diffusion of $\mathrm{Cl}^{-}$ effectively compared to SF mixed mortar.

After the 30 days period of ACTM, the corrosion cracks (crack width $>0.2 \mathrm{~mm}$ ) in OPC mortar applied beam were observed. Micro level corrosion cracks (crack width $<0.05 \mathrm{~mm}$ ) were observed in the beams repaired with $\mathrm{SF}$ 
mixed mortar and there was no surface corrosion crack in the beam repaired with FA mixed mortar. These results imply that the RC beam repaired by OPC mortar was totally corroded, and the beams repaired with SF mixed mortar was slightly corroded where the beam repaired with the FA mixed mortar seems to be free from the corrosion.

The rust production (both rust weight and reduction in bar diameter) of OPC mortar applied beam is higher value compared to FA and SF mixed mortars applied beams (Table 2). Further, rust production of FA mixed mortar applied beam is negligible value (i.e., $\mathrm{W}=1.76$ $\left.\mathrm{g}, \Phi_{\mathrm{r}}=0.19 \mathrm{~mm}\right)$ compared to OPC mortar applied beam (i.e., $\mathrm{W}=7.8 \mathrm{~g}, \Phi_{\mathrm{r}}=2.43 \mathrm{~mm}$ ). This implies that the OPC mortar applied RC beam was continued corrosion while FA mixed mortar prevents production of rust.

According to Table 3, possible corrosion rate of OPC mortar (i.e., $1.8 \mathrm{k}$ Ohms cm) applied beam is very high (resistivity $<5 \mathrm{k}$ ohms $\mathrm{cm}$ ) while that is high (resistivity between 5 to $10 \mathrm{k} \mathrm{Ohms}$ $\mathrm{cm}$ ) in the RC beams repaired by using $10 \%$ of SF mixed mortar (i.e., $9.05 \mathrm{k}$ Ohms cm) and moderate to lower (resistivity between 10 to 20 $\mathrm{k}$ ohms cm) in the RC beams repaired by $50 \%$ of FA based mortar (i.e., $12 \mathrm{k}$ Ohms $\mathrm{cm}$ ). These results imply that the internal corrosion level of the beams repaired by FA based mortar has significantly reduced.

Charge passed through of $15 \%$ of SF and $75 \%$ of FA mixed mortar are lower values compared to that of OPC mortar (Figure 12). Therefore, chloride ion diffusion through these mortars (75\% of FA and $15 \%$ of SF mixed mortars) is lower compared to OPC mortar. Compared to OPC mortar, $75 \%$ of FA mixed mortar reduces the diffusion of $\mathrm{Cl}^{-}$through mortars by $48.5 \%$ and $15 \%$ of SF mixed mortar reduces $43.1 \%$. The uses of FA and SF with mortars reduce the diffusion of $\mathrm{Cl}^{-}$into concrete, which prevents the corrosion.

The pozzolanic reaction in FA and SF converts the calcium hydroxide in to more of the calcium silicate hydroxide (CSH), thus increase the strength which leading to reduce permeability. Further, FA and SF have fine particles which might have contributed to minimize the voids in mortars. Therefore, the replacement of both FA and SF admixtures increases the density of mortars. As a result, FA and SF mixed mortars effectively minimize the diffusion of $\mathrm{Cl}^{-}$ions, moisture, oxygen and aggressive chemicals into concrete compared to OPC mortar.
Considering the results of $\mathrm{Cl}^{-}$concentration, rust production, resistivity and charge passed values, the corrosion prevention performances of FA mixed mortar is a high value compared to SF mixed mortar. Jansen and Pratt [7] showed, by using microstructure studies, that the reaction product from the pozzolanic reaction of FA was CSH (calcium silicate hydrates) and $\mathrm{CAH}$ (calcium aluminate hydrates), where the latter can give rise to increased chloride binding capacity. With the increase of SF amount, the producing of $\mathrm{CAH}$ decreased which cause to decrease the binding capacity. Therefore, FA mixed mortar minimizes the diffusion of $\mathrm{Cl}^{-}$compare to $\mathrm{SF}$ mixed mortar. In addition, coal power generation has recently been established in Sri Lanka and one of by-products of the coal power plants is FA. Hence FA can be easily found in Sri Lanka with minimum cost.

\subsection{Retrofitting Methods}

Before performing ACTM, both free and total $\mathrm{Cl}^{-}$concentrations were less than the threshold value of $1.2 \mathrm{~kg} / \mathrm{m}^{3}$ (Figures 13 and 14). After performing the ACTM, free and total $\mathrm{Cl}^{-}$ concentrations of all test beams were greater than the threshold value of the $\mathrm{Cl}^{-}$ concentration resulting to initiate corrosion. After retrofitting, the total $\mathrm{Cl}^{-}$concentrations in these beams reduced to a value less than the threshold value. This implies that the applying of retrofitting prevents or minimizes further corrosion of $\mathrm{RC}$ beams by reducing $\mathrm{Cl}^{-}$ concentration near to embedded steel reinforcement bars.

Table 7- Percentages (\%) of chloride ion removed by retrofitting methods

\begin{tabular}{|c|c|c|c|c|}
\hline \multirow{3}{*}{ 升 } & \multicolumn{4}{|c|}{$\mathrm{Cl}^{-}$concentrations as percentages $(\%)$} \\
\hline & \multicolumn{2}{|c|}{ CP method } & \multicolumn{2}{|c|}{ ECE method } \\
\hline & Free & Total & Free & Total \\
\hline 20 & 76.48 & 49.33 & 83 & 68.53 \\
\hline 40 & 72.65 & 57.01 & 75.98 & 63.2 \\
\hline 60 & 69.84 & 47.2 & 71.69 & 52.27 \\
\hline
\end{tabular}

In the current experimental investigation, 20 $\mathrm{mm}$ depth level is the most critical level as the clear cover thickness provided is $20 \mathrm{~mm}$. In this region, the ECE retrofitting technique removed $68.5 \%$ of total and $83 \%$ of free $\mathrm{Cl}^{-}$from the corroded beams (i.e., after performing ACTM) while the CP retrofitting technique removed $49.3 \%$ of total and $76.5 \%$ of free $\mathrm{Cl}^{-}$(Table 7 ). Clemena and Jackson [2], have carried out ECE method $\left(\mathrm{Ca}(\mathrm{OH})_{2}\right.$ with $\mathrm{H}_{2} \mathrm{O}$ were used as 
chemical media) on a 28-year old bridge deck located in Arlington, Virginia and observed similar results for free $\mathrm{Cl}^{-}$ion concentration where ECE removes $\mathrm{Cl}^{-}$in concrete with about $75.8 \%$ of $\mathrm{Cl}^{-}$at the 6 to $19 \mathrm{~mm}$ depth, and $72.2 \%$ of $\mathrm{Cl}^{-}$at the 19 to $32 \mathrm{~mm}$ depth. In their study, ECE method was conducted using titanium mesh (i.e., as anode) which is better than copper mesh used in the current study. However, use of copper mesh for the anode is cost effective rather than use of titanium mesh. Compared to the current study $\left(\mathrm{Cl}^{-}\right.$ concentration of corroded RC beam was 1.64 $\mathrm{kg} / \mathrm{m}^{3}$ at 0 to $20 \mathrm{~mm}$ depth), the bridge deck was highly chloride contaminated (initial $\mathrm{Cl}^{-}$ concentration was $4.97 \mathrm{~kg} / \mathrm{m}^{3}$ at 6 to $19 \mathrm{~mm}$ depth). Therefore, it is easier to remove free $\mathrm{Cl}^{-}$ ions from bridge deck. Further, in the previous study (Clemena and Jackson [2]) ECE was conducted for bridge deck over a long period (58 days) while it was 23 days in the current study. However, removal of $\mathrm{Cl}^{-}$is less $(75.8 \%)$ for bridge deck than that of the current study $(83 \%)$ and final $\mathrm{Cl}^{-}$concentration (after performing ECE) of bridge deck was $1.2 \mathrm{~kg} / \mathrm{m}^{3}$ (which was equal to threshold value), while it was $0.516 \mathrm{~kg} / \mathrm{m}^{3}$ in the current study. It seems that conducting the ECE for bridge deck in-situ condition and for current study in the laboratory with less $\mathrm{Cl}^{-}$contamination condition would cause the slight variation in results for bridge deck and test beams.

When the current was supplied to the CP setup, the steel reinforcement became cathode and the chloride ions are redistributed away from the steel bars and reached towards the copper anode (at concrete surface area). This might contribute to the reduction in chloride ion concentration near the steel reinforcements. In ECE retrofitting technique, the copper mesh is covered by using chemical media (calcium hydroxide) and the chloride ions which approached towards the copper mesh are removed by calcium hydroxide by producing $\mathrm{CaCl}_{2}$. This might attribute to increase the efficiency of removing chloride ions by the ECE method compared to that of the CP method.

After retrofitting (CP and ECE methods), the free $\mathrm{Cl}^{-}$concentration of test beams decreases nearly down to the $\mathrm{Cl}^{-}$concentration of beams observed at 28 days curing (Figure 13). The retrofitting methods are based on the electrical system and the free $\mathrm{Cl}^{-}$contributes directly to conduct the current across concrete area. Therefore, admittedly, the free $\mathrm{Cl}^{-}$are redistributed from steel reinforcements and reached towards the concrete surface area.
These free $\mathrm{Cl}^{-}$are removed by calcium hydroxide layer by producing $\mathrm{CaCl}_{2}$. On the other hand, free $\mathrm{Cl}^{-}$causes the corrosion of steel reinforcement. The bonded chloride ions may not contribute to the corrosion process. Possibility of removing free chloride ions by these retrofitting techniques is an advantage.

The weight of rust production and reduction in bar diameter of retrofitted RC beams are lesser compared to control RC beam (Table 4). This implies that retrofitting methods contribute to prevent further corrosion. The resistivity of all RC beams (Control beams and retrofitted beams) is lower than $5 \mathrm{k} \mathrm{Ohms} \mathrm{cm}$ (Table 5), implying the possible corrosion rate of all beams is very high. Before retrofitting ( $\mathrm{CP}$ and ECE methods), RC beams were subjected to ACTM in order to make sure the RC beams were already corroded. After retrofitting, the beams were again subjected to ACTM. This allowed the Resistivity meter to measure the resistivity at both corrosion stages: before retrofitting and after retrofitting. The observed corrosion rate was significantly high value, possibly because the corrosion was accelerated by conducting the ACTM. Further, considering the measured values, control beam shows very lower value, means it would be highly corroded than other two beams.

The free $\mathrm{Cl}^{-}$conduct the current through the concrete area, hence considering the current distribution through retrofitted RC beams, the free $\mathrm{Cl}^{-}$were redistributed away from the embedded steel reinforcement (cathode) area towards concrete surface area (copper mesh anode). Therefore, the reduction in current of ECE and CP methods implied the reduction in $\mathrm{Cl}^{-}$concentrations. The efficiency of removing chloride ion (based on the current reduction) for CP method was $46.7 \%$, while it was $66 \%$ for ECE method. Time taken to remove $\mathrm{Cl}^{-}$by $\mathrm{CP}$ method is around 31 days while it is around 23 days for the ECE method indicating that the ECE method removes $\mathrm{Cl}^{-}$within shorter time period compared to the $\mathrm{CP}$ method.

In both CP and ECE methods, the potential of embedded steel reinforcement were shifted to negative direction, making the steel reinforcement became cathode with time. When the steel reinforcement bars totally charge with negative ions, further continuation of current might help to produce hydroxyl ions (with the presence of water and oxygen) near the reinforcement bars, resulted in creating of alkaline conditions. This leads to re-passivate the steel reinforcements, produce iron oxide 
$\left(\mathrm{Fe}_{2} \mathrm{O}_{3}\right)$ film surrounding the steel reinforcement bars, prevent the diffusion of oxygen to steel bar area and hence prevent the further corrosion. In addition, these retrofitting methods help to redistribute the $\mathrm{Cl}^{-}$from embedded steel reinforcement towards the concrete surface. The $\mathrm{Cl}^{-}$which approached to concrete surface is removed by calcium hydroxide as producing calcium chloride $\left(\mathrm{CaCl}_{2}\right)$. The use of calcium hydroxide as chemical media in ECE retrofitting method cause to increase the efficiency of the method, compared to $\mathrm{CP}$ method.

\section{Conclusions}

As repairing methods, Fly Ash (FA) and Silica Fume (SF) mixed mortars were developed and Cathodic Protection (CP) and Electrochemical Chloride ion Extraction (ECE) were conducted as retrofitting methods for corroded RC structures. Efficiency of both repairing and retrofitting methods was evaluated by measuring free and total $\mathrm{Cl}^{-}$concentrations and rust production. Efficiency of the methods was further evaluated by conducting resistivity measurements and Rapid Chloride Permeability Test (RCPT) relevant to the repairing mortars and current measurement relevant to the retrofitting methods.

The FA and SF mixed mortars minimize the corrosion of RC structures by preventing the diffusion of $\mathrm{Cl}^{-}$into concrete. It was found that the $50 \%$ of FA mixed mortar performs better compared to the $10 \%$ of SF mixed mortar. With the use of coal power generation, recently established in Sri Lanka, FA can be easily found with minimum cost, as one of by-product of the coal power plants is FA. The $\mathrm{CP}$ and ECE methods remove around $49 \%$ and $69 \%$ of total $\mathrm{Cl}^{-}$, respectively. These retrofitting methods prevent further corrosion of RC structures by removing $\mathrm{Cl}^{-}$near the steel reinforcements and producing alkaline conditions around the steel bars which helps to form iron oxide film around the steel bars. With ECE method, calcium hydroxide helps to increase the efficiency of the CP method process by nearly $20 \%$ with removing the $\mathrm{Cl}^{-}$approached towards copper mesh area.

The spalled and delaminated areas of corroded RC structures can be repaired by using FA mixed mortars and the chloride contaminated concrete that is still sound can remain in place by using ECE method, effectively. The use of calcium hydroxide as chemical media with ECE method accelerates the performances of $\mathrm{CP}$ method. Experimental investigation conducted in this study confirmed that the use of both FA based repair mortar and ECE retrofitting more effectively help to prevent the chloride ions diffusion into concrete and enhancing the service life of structures.

\section{Acknowledgments}

The authors wish to express their special thanks to Research Grant of Transforming University of Ruhuna to International Status (TURIS-2011) for providing necessary funds and Faculty of Engineering, University of Ruhuna for providing technical assistance for carrying out the research work presented in this paper. Furthermore authors' sincere thank goes to Prof. Hiroshi Mutsuyoshi, Department of Civil and Environmental Engineering, Saitama University, Japan for providing necessary experimental materials and technical guidance.

\section{References}

1. Aggarwal V., Gupta S. M. and Sachdeva S.N., "Concrete Durability through High Volume Fly Ash Concrete (HVFC) - A Literature Review", International Journal of Engineering Science and Technology, Vol. 2(9), 2010, pp. 4473-4477.

2. Clemena G. G. and Jackson D. R., "Pilot Applications of Electrochemical Chloride Extraction on Concrete Bridge Decks in Virginia", Transportation Research Record, No. 1597, 1997, pp. 70-76

3. Detwiler R. J., Whiting D. A. and Lagergen E.S., "Statistical Approach to Ingress of Chloride Ions in Silica Fume Concrete for Bridge Decks", ACI Materials Journal, Vol. 96, No. 6, Nov.-Dec. 1999, pp.670-675.

4. Florida Department of Transportation (FDOT), “An Accelerated Laboratory Method for Corrosion of Reinforced Concrete using Impressed Current", Manual of Florida Sampling and Testing Methods, Tallahassee, FL, September 2000, pp. 6.

5. Ganesan K., Rajagopal K. and Thangavel K., "Chloride Resisting Concrete Containing Rice Husk Ash and Bagasse Ash", Indian Journal of Engineering \& Materials Sciences, Vol.14, June 2007, pp.257-265.

6. Gunasekara M. P. C. M., Mutsuyoshi H. and Sumita A., "Renovate RC Structures with Newly Developed Mortar Considering Chloride Binding and Inverse Diffusion 
Phenomenon", International Conference on Structural Engineering, Construction and Management (ICSECM), Kandy, Sri Lanka, December 2011.

7. Jansen H. U. and Pratt P. L., "The Binding of Chloride Ions by Pozzolanic Product in Fly Ash Cement Blends", Advances in Cement Research, Vol. 2, No. 7, 1989, pp.121-129.

8. Jennifer L. K., David D. and Carl E. L., "Evaluation of Corrosion Protection Methods for Reinforced Concrete Highway Structures", Structural Engineering and Engineering Materials, SM Report No.58, University of Kansas Center for Research, Inc., Lawrence, Kansas, May 2000.

9. NDT James Instruments Inc., “Instruction Manual - RM-8000 Resistivity Meter", James Instruments Inc., Chicago, U.S.A.

10. Sahmaran M., Li V. C. and Andrade C., "Corrosion Resistance Performance of SteelReinforced Engineered Cementitious Composite Beams", ACI Materials Journal, V. 105, No. 3, May-June 2008, pp. 243-250.

11. Saraswathy V. and Song H., "Evaluation of Cementitious Repair Mortars for Corrosion Resistance", PortugaliaeElectrochimicaActa, 26/5, June 2008, pp. 417-432.

12. Veerachai L., Toshimitsu S., Yuichi T. and Masayasu O., "Estimation of Corrosion in Reinforced Concrete by Electrochemical Techniques and Acoustic Emission", Journal of Advanced Concrete Technology, Vol. 3, No.1, February 2005, pp.137-147.

13. Virmani Y. P. and Clemena G. G., "Corrosion Protection-Concrete Bridges," Report No. FHWA-RD-98-088, Federal Highway Administration, Washington, D.C., September 1998. 